\title{
A marked increase in gastric fluid volume during cardiopulmonary bypass
}

\author{
Kazuyoshi Hirota, ${ }^{1, *}$ Mihoko Kudo, $^{1}$ Hiroshi Hashimoto ${ }^{1}$ and Tetsuya Kushikata ${ }^{1}$ \\ 'Department of Anesthesiology, Hirosaki University Graduate School of Medicine, Hirosaki 036-8562, Japan
}

(Received 2 August, 2010; Accepted 17 October, 2010; Published online 26 April, 2011)

\begin{abstract}
Major physiological stress occurs during cardiac surgery with cardiopulmonary bypass. This is related to hypothermia and artificial organ perfusion. Thus, serious gastrointestinal complications, particularly upper gastrointestinal bleeding, sometimes follow cardiac surgery. We have compared the antisecretory effects of a preanesthetic $\mathrm{H}_{2}$ antagonist (roxatidine, cardiopulmonary bypass- $\mathrm{H}_{2}$ group, $n=15$ ) and a proton pump inhibitor (rabeprazole, cardiopulmonary bypass-PPI group, $n=15$ ) in patients undergoing cardiac surgery with cardiopulmonary bypass, and also compared in patients undergoing a off-pump coronary artery bypass graft surgery (off-pump cardiopulmonary bypass- $\mathrm{H}_{2}$ group, $n=15$ ). Gastric pH (5.14 \pm 0.61$)$ and gastric fluid volume $(13.2 \pm 2.4 \mathrm{~mL})$ at the end of surgery in off-pump cardiopulmonary bypass- $\mathrm{H}_{2}$ groups was significantly lower and higher than those in both cardiopulmonary bypass- $\mathrm{H}_{2}(6.25 \pm 0.54,51.3 \pm 8.0 \mathrm{~mL})$ and cardiopulmonary bypass-PPI $(7.29 \pm 0.13,63.5 \pm 14.8 \mathrm{~mL})$ groups, respectively although those variables did not differ between groups after the induction of anesthesia. Plasma gastrin $(142 \pm 7 \mathrm{pg} / \mathrm{mL})$ at the end of surgery and maximal blood lactate levels $(1.50 \pm$ $0.61 \mathrm{mM}$ ) in off-pump cardiopulmonary bypass $-\mathrm{H}_{2}$ group were also significantly lower than those in both cardiopulmonary bypass $-\mathrm{H}_{2}$ $(455 \pm 96 \mathrm{pg} / \mathrm{mL}, 3.97 \pm 0.80 \mathrm{mM})$ and cardiopulmonary bypass-PPI ( $525 \pm 27 \mathrm{pg} / \mathrm{mL}, 3.15 \pm 0.44 \mathrm{mM}$ ) groups, respectively. In addition, there was a significant correlation between gastric fluid volume and maximal blood lactate $(r=0.596)$. In conclusion, cardiopulmonary bypass may cause an increase in gastric fluid volume which neither $\mathrm{H}_{2}$ antagonist nor PPI suppresses. A significant correlation between gastric fluid volume and maximal blood lactate suggests that gastric fluid volume may predict degree of gastrointestinal tract hypoperfusion.
\end{abstract}

Key Words: cardiopulmonary bypass, gastrointestinal ischemia, gastric acidity, $\mathrm{H}_{2}$ antagonists, proton pump inhibitors

M ajor physiological stress occurs during cardiac surgery with 1 cardiopulmonary bypass (CPB). This is related to hypothermia and artificial organ perfusion. Several studies show that serious gastrointestinal complications, particularly upper gastrointestinal (GI) bleeding, follow cardiac surgery and these complications can lead to high rates of morbidity and mortality. ${ }^{(1,2)}$ In addition, Ueki and colleagues ${ }^{(3)}$ reported that secretion of gastric juice increased significantly from $3.8 \pm 1.3$ to $12.4 \pm 4.0 \mathrm{ml} / \mathrm{h}$ after induction of extracorporeal circulation. Thus, a risk for acid aspiration pneumonia may increase after $\mathrm{CPB}$.

Aspirin and anti-platelet drugs are commonly used for patients with coronary heart disease. Proton pump inhibitor (PPI) and $\mathrm{H}_{2}$ antagonists are recommended for the prevention of nonsteroidal antiinflammatory drugs (NSAIDs)-related ulcer. ${ }^{(4)}$ However, longterm $\mathrm{H}_{2}$ antagonist medication produces a reduction in antisecretory efficacy or tolerance. ${ }^{(5,6)}$ We have previously reported that patients receiving $\mathrm{H}_{2}$ antagonists for more than 4 weeks show resistance to preanesthetic $\mathrm{H}_{2}$ antagonist treatment, used for acid aspiration pneumonia prophylaxis. ${ }^{(7)}$ If patients develop tolerance then preanesthetic $\mathrm{H}_{2}$ antagonist medication would be essentially useless and an alternative would be required. In contrast, PPIs may be a suitable alternative as they produce a similar or more potent anti-secretory effect on gastric acid secretion than $\mathrm{H}_{2}$ antagonists. ${ }^{(8,9)}$ These reports ${ }^{(8,9)}$ also suggest that tolerance to PPI treatment would not develop as PPIs inhibit the $\mathrm{H}^{+} / \mathrm{K}^{+}$-adenosine triphosphatase pump, which is the final step in gastric acid secretion from the parietal cell. ${ }^{(10)}$

Thus, we hypothesized that PPI may be more effective for prophylaxis of perioperartive stress-induced GI bleeding and acid aspiration pneumonia than $\mathrm{H}_{2}$ antagonist in patients undergoing cardiac surgeries with CPB. Therefore, in the present study, to test our hypothesis, we have compared the antisecretory effects of a preanesthetic $\mathrm{H}_{2}$ antagonist (roxatidine) and a PPI (rabeprazole) in patients undergoing cardiac surgery and also compared gastric $\mathrm{pH}$ and volume in patients with and without $\mathrm{CPB}$.

\section{Materials and Methods}

With University Ethics Committee approval and informed consent, 45 adult patients undergoing cardiac surgery were recruited in the study. Number of patients in each group was determined by power analysis using our previous study data. ${ }^{(5)}$ Thirty patients undergoing cardiac surgery under CPB were randomly assigned to two groups: $\mathrm{CPB}-\mathrm{H}_{2}$ and $\mathrm{CPB}-\mathrm{PPI}$ group $(n=15$ each). Another 15 patients were scheduled to undergoing off-pump coronary artery bypass grafting (OPCAB) surgery (OPCAB- $\mathrm{H}_{2}$ group). In the $\mathrm{CPB}-\mathrm{H}_{2}$ and $\mathrm{OPCAB}-\mathrm{H}_{2}$ groups, patients were given roxatidine $75 \mathrm{mg}$ orally at 9:00 $\mathrm{pm}$ on the day before the surgery and $2 \mathrm{~h}$ before the induction of anesthesia. In the CPB-PPI group, patients were premedicated with rabeprazole $20 \mathrm{mg}$ orally at 9:00 pm on the day before the surgery and $2 \mathrm{~h}$ before the induction of anesthesia. Because only roxatidine has been approved as an oral preanesthetic $\mathrm{H}_{2}$ antagonist by our Ministry of Health, Labor and Welfare in Japan, famotidine or ranitidine was not used. All patients were hospitalized for at least the night before surgery and were fasted from the first anesthetic premedication (i.e., 9:00 pm). The researchers and patients were blinded to preanesthetic medication.

Anesthesia was induced with propofol $0.5-1.5 \mathrm{mg} / \mathrm{kg}$, ketamine $0.5-1.0 \mathrm{mg} / \mathrm{kg}$, and fentanyl $5 \mu \mathrm{g} / \mathrm{kg}$ and maintained with propofol 3-7 $\mathrm{mg} \cdot \mathrm{kg}^{-1} \cdot \mathrm{h}^{-1}$, ketamine $0.5-1.0 \mathrm{mg} \cdot \mathrm{kg}^{-1} \cdot \mathrm{h}^{-1}$, and fentanyl 4-8 $\mu \mathrm{g} / \mathrm{kg}$. The trachea was intubated after muscle relaxation facilitated with vecuronium $0.1 \mathrm{mg} / \mathrm{kg}$ IV. Muscle relaxation was maintained with an IV bolus of vecuronium that was given $1 \mathrm{mg}$ every $30 \mathrm{~min}$. A gastric tube (Argyle ${ }^{\circledR}$ Salem Sump Tube, Japan

To whom correspondence should be addressed.

E-mail: hirotak@cc.hirosaki-u.ac.jp 
Table 1. Patient characteristics

\begin{tabular}{|c|c|c|c|c|c|c|c|c|}
\hline \multirow{2}{*}{ Group } & \multirow{2}{*}{$n$} & \multirow{2}{*}{$\begin{array}{c}\operatorname{Sex} \\
(M / F)\end{array}$} & \multirow{2}{*}{$\begin{array}{c}\text { Age } \\
\text { (yr) }\end{array}$} & \multirow{2}{*}{$\begin{array}{c}\mathrm{Ht} \\
(\mathrm{cm})\end{array}$} & \multirow{2}{*}{$\begin{array}{l}\text { Wt } \\
(\mathrm{kg})\end{array}$} & \multicolumn{3}{|c|}{ Duration (min) } \\
\hline & & & & & & Ane & Surg & CPB \\
\hline $\mathrm{CPB}-\mathrm{H}_{2}$ & 15 & $4 / 11$ & $60 \pm 12$ & $157 \pm 10$ & $56 \pm 14$ & $439 \pm 88$ * & $357 \pm 84^{*}$ & $189 \pm 61$ \\
\hline CPB-PPI & 15 & $7 / 8$ & $64 \pm 11$ & $158 \pm 9$ & $64 \pm 11$ & $441 \pm 146 *$ & $372 \pm 141$ * & $200 \pm 103$ \\
\hline $\mathrm{OPCAB}-\mathrm{H}_{2}$ & 15 & $5 / 10$ & $67 \pm 10$ & $157 \pm 9$ & $60 \pm 10$ & $342 \pm 57$ & $273 \pm 55$ & $(-)$ \\
\hline
\end{tabular}

Data are either number of patients or Mean \pm SD as appropriate. Ht: height, Wt: weight, Ane: anesthesia, Surg: surgery, CPB: cardiopulmonary bypass, (-): no application, * $p<0.01$ vs OPCAB- $\mathrm{H}_{2}$.

Sherwood, Tokyo, Japan) was placed into the stomach twice after tracheal intubation and the end of surgery as the first gastric tube was removed before insertion of transesophageal echocardiography probe. The position of tip of gastric tube was verified by auscultation of the epigastrium during insufflation of air.

Gastric fluid was obtained by aspiration using a 10 or $50 \mathrm{~mL}$ syringe while changing the patient's position (supine, Trendelenburg and reverse Trendelenburg, and right and left 20 degree semilateral positions) and with insufflation of $50 \mathrm{~mL}$ air plus upper-abdominal massage. The volume of gastric contents was recorded as well as the $\mathrm{pH}$ value, measured using a $\mathrm{pH}$ meter with $0.01 \mathrm{pH}$ unit precision over the entire $\mathrm{pH}$ range (Ecoscan $\mathrm{pH} 5$ pH6; Iuchi Seieido Co., Ltd., Osaka, Japan) that was calibrated each morning.

Arterial blood was collected simultaneously and centrifuged at $3,000 \mathrm{rpm}$ for $10 \mathrm{~min}$ at $-10^{\circ} \mathrm{C}$ to separate plasma, which was kept frozen at $-70^{\circ} \mathrm{C}$ until assay. Plasma gastrin concentrations were analyzed using a commercially available enzyme-linked immunosorbent assay (Peninsula Laboratories Inc., San Carlos, CA) with a minimum sensitivity, inter- and intraassay coefficient of variation of $7.27 \mathrm{pg} / \mathrm{mL}, 6.5 \%$ and $3.7 \%$, respectively. In addition, arterial blood lactate levels were measured every hour.

Data are presented as mean \pm SEM. Statistical analysis was performed using factorial or repeated one way ANOVA and paired or unpaired $t$ test as appropriate, with $p<0.05$ considered significant.

\section{Results}

There were no significant differences between groups with respect to sex, age, height, and weight except duration of anesthesia and surgery. These data are summarized in Table 1. The type of cardiac surgery is also listed in Table 2.

Gastric $\mathrm{pH}$ and volume at the end of surgery in $\mathrm{OPCAB}-\mathrm{H}_{2}$ groups was significantly lower and higher than those in both CPB$\mathrm{H}_{2}$ and CPB-PPI groups, respectively although those variables did not differ between groups after the induction of anesthesia (Fig. $1 \mathrm{~A}$ and B). Plasma gastrin and maximal blood lactate levels were also significantly lower in OPCAB- $\mathrm{H}_{2}$ group than those in both $\mathrm{CPB}-\mathrm{H}_{2}$ and $\mathrm{CPB}-\mathrm{PPI}$ groups (Fig. $1 \mathrm{C}$ and $\mathrm{D}$ ). In addition, there was a significant correlation between gastric fluid volume and maximal blood lactate level (Fig. 2; $\mathrm{r}=0.596 ; p<0.01$ ).

There were fewer patients showing critical factors for acid aspiration pneumonia $(\mathrm{pH}<2.5$ or gastric fluid volume $>25 \mathrm{~mL})$ in the OPCAB- $\mathrm{H}_{2}$ group (Table 3 ).

\section{Discussion}

CPB patients (CPB- $\mathrm{H}_{2}$ and CPB-PPI groups) had higher gastric $\mathrm{pH}$ and volume compared to those in the OPCAB- $\mathrm{H}_{2}$ group. If $\mathrm{H}_{2}$ antagonist and PPI were effective, gastric fluid volume should have been reduced with higher $\mathrm{pH}$. Thus, higher gastric $\mathrm{pH}$ may not imply that these anti-acid agents suppressed gastric acid secretion. Where did gastric fluid volume come from? Several reports $^{(11-14)}$ indicate that the CPB causes intestinal hypoperfusion which impairs small intestinal transport and increases intestinal permeability. Tsunooka and colleagues ${ }^{(14)}$ reported that serum
Table 2. Details of cardiac procedures

\begin{tabular}{lccc}
\hline \multirow{2}{*}{ Type of cardiac surgery } & \multicolumn{3}{c}{ Group } \\
\cline { 2 - 4 } CABG & CPB-H & CPB-PPI & OPCAB- ${ }_{2}$ \\
\hline CABG + Dor's ope & 1 & 1 & 15 \\
CABG + Dor's ope + MVP & 2 & 0 & $(-)$ \\
CABG + AVR & 1 & 0 & $(-)$ \\
CABG + MVP & 2 & 4 & $(-)$ \\
AVR & 1 & 1 & $(-)$ \\
TVR & 1 & 1 & $(-)$ \\
MVR or MVP & 1 & 0 & $(-)$ \\
MVR + TAP & 4 & 1 & $(-)$ \\
MVR + AVR & 2 & 0 & $(-)$ \\
ASD & 0 & 1 & $(-)$ \\
ASD + VSD & 0 & 1 & $(-)$ \\
ASD + MVP & 0 & 1 & $(-)$ \\
As-Ao Replacement + AVR & 0 & 1 & $(-)$ \\
Ds-Ao Replacement & 0 & 1 & $(-)$ \\
Total Arch Replacement & 0 & 1 & $(-)$ \\
CABG coronarV arterV bVass & 0 & 1 & $(-)$
\end{tabular}

CABG: coronary artery bypass grafting, ope: operation, MVR: mitral valve replacement, MVP: mitral valve plasty, AVR: aortic valve replacement, TAP: tricuspid annuloplasty, TVR: tricuspid valve replacement ASD: atrial septal defect, VSD: ventricular septal defect, As-Ao: ascending aorta, Ds-Ao: descending aorta, $(-)$ : no application.

diamine oxidase activity, an index of small intestinal ischemia, rose significantly during the $\mathrm{CPB}$ in patients undergoing coronary artery bypass grafting. The activity was unchanged in patients undergoing OPCAB. In addition, serum lactate mirrored the changes in diamine oxidase activity. Similarly, blood lactate was significantly higher in the CPB groups than that in the OPCAB group in the present study. As lactate production increases as a consequence of tissue hypoxia, high blood lactate levels may also indicate intestinal hypoperfusion during CPB. ${ }^{(14)}$ As there was a significant correlation between gastric fluid volume and maximal blood lactate levels in the present study, intestinal hypoperfusion due to $\mathrm{CPB}$ could increase GI microvascular permeability to increase gastric fluid volume. Therefore, either gastric fluid volume or blood lactate may be an index of GI tract hypoperfusion.

Critical factors for acid aspiration pneumonia in adults have been considered to comprise gastric $\mathrm{pH}$ below 2.5 and a fluid volume above $25 \mathrm{~mL} .^{(15)}$ In the present study, 12 and 10 of 15 patients with more than $25 \mathrm{~mL}$ of gastric contents in the CPB- $\mathrm{H}_{2}$ and CPB-PPI groups have a higher postoperative risk of acid aspiration pneumonia. Into the OPCAB- $\mathrm{H}_{2}$ group only 2 of 15 patients had gastric contents in excess of $25 \mathrm{~mL}$. Thus, gastric tube should be inserted after removal of transesophageal echocardiographic probe.

To determine the precise mechanism regarding the increase of gastric fluid volume by CPB, we should have placed the gastric tube just after termination of CPB rather than just before the end 

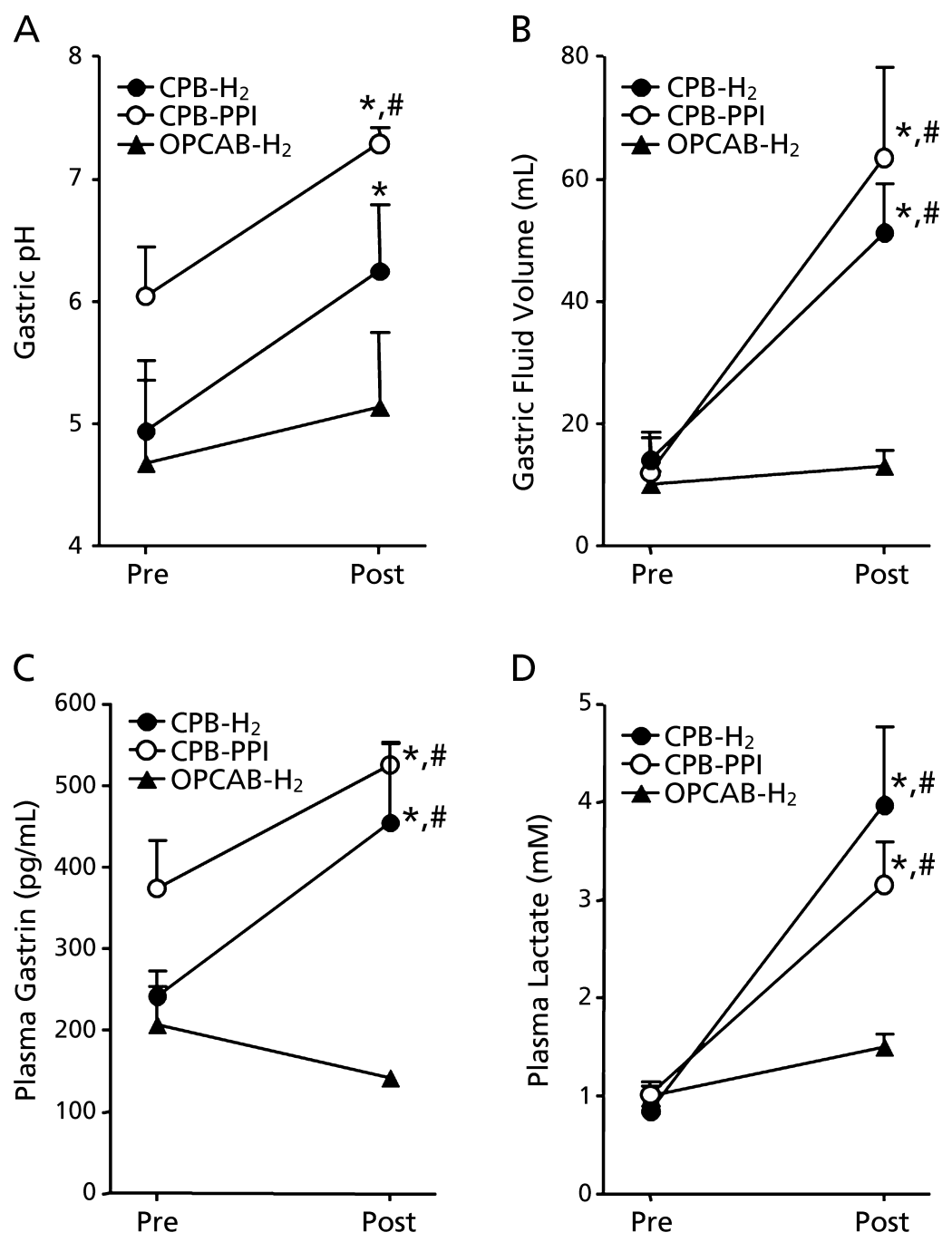

Fig. 1. Changes in gastric $\mathrm{pH}(\mathrm{A})$, gastric fluid volume (B), plasma gastrin (C) and maximal blood lactate level (D) at the beginning and end of surgery. Pre: before cardiopulmonary bypass (CPB), Post: after cessation of CPB, Mean \pm SEM, ${ }^{*} p<0.01$ vs Pre, ${ }^{\#} p<0.01$ vs OPCAB- $\mathrm{H}_{2}$ group.

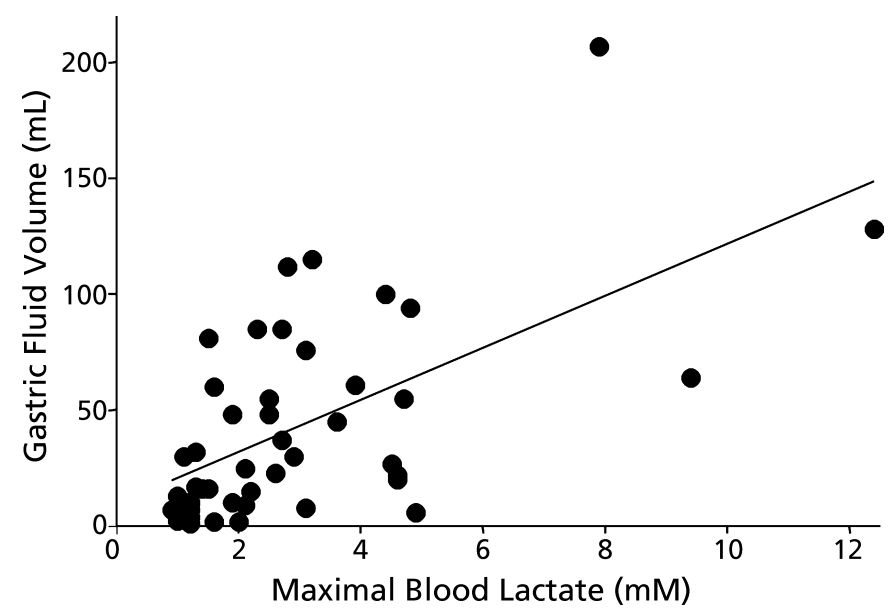

Fig. 2. Correlation between gastric fluid volume and maximal blood lactate $(r=0.596, p<0.01)$. of surgery in the present study. However, as OPCAB-H2 group data clearly suggest that an increase in gastric fluid volume may be due to $\mathrm{CPB}$ as cardiac surgery per se would not increase gastric fluid volume.

The present data indicate that both $\mathrm{H}_{2}$ antagonist and PPI cannot inhibit an increase in gastric fluid volume. Should these agents be given as anesthetic premedication? If neither are given, most of patients would have a high risk of acid aspiration pneumonia during the induction of anesthesia as we previously found that patients without prophylaxis showed low gastric $\mathrm{pH}(2.2 \pm 1.2)$ and high volume $(20 \pm 18 \mathrm{~mL}) .^{(16)}$ In addition, the chief GI complication following CPB is GI bleeding secondary to gastric or duodenal ulceration. ${ }^{(17)}$ Therefore, perioperative gastric acid suppression is necessary. Which anti-acid agent is suitable to suppress gastric acidity in patients undergoing cardiac surgery $\mathrm{H}_{2}$ antagonist or PPI? Wagner and colleagues ${ }^{(15)}$ reported that perioperative administration of famotidine $\left(\mathrm{H}_{2}\right.$ antagonist $)$ suppresses gastric secretion in cardiac patients. Hata and colleagues ${ }^{(18)}$ compared three agents $(n=70$ each): teprenone $150 \mathrm{mg}$ /day (mucosal protection), ranitidine $300 \mathrm{mg} /$ day $\left(\mathrm{H}_{2}\right.$ antagonist) and rabeprazol $10 \mathrm{mg}$ /day (PPI) to prevent postoperative the upper GI complicationsin patients undergoing cardiac surgery with $\mathrm{CPB}$. They found that the incidences of hemorrhagic gastritis and active ulceration were significantly lower in patients with rabeprazole. 
Table 3. Number of patients showing critical factors for acid aspiration pneumonia and hypergastrinemia after induction of anesthesia (Pre) and the end of surgery (Post)

\begin{tabular}{lccccc}
\hline Group & & $\mathrm{pH}<2.5$ & $\mathrm{GV}>25 \mathrm{~mL}$ & $\mathrm{pH}<2.5$ or GV $>25 \mathrm{~mL}$ & Hypergastrinemia \\
\hline CPB-H & Pre & $3 / 15$ & $3 / 15$ & $6 / 15$ & $9 / 15$ \\
& Post & $2 / 15$ & $12 / 15$ & $12 / 15$ & $12 / 15$ \\
CPB-PPI & Pre & $1 / 15$ & $3 / 15$ & $4 / 15$ & $12 / 15$ \\
& Post & $10 / 15$ & $10 / 15$ & $12 / 15$ \\
OPCAB-H 2 & Pre & $4 / 15$ & $2 / 15$ & $5 / 15$ & $5 / 15$ \\
& Post & $2 / 15$ & $2 / 15 *$ & $3 / 15^{*}$ & $2 / 15^{*}$ \\
\hline
\end{tabular}

Number/Total, pH: gastric $\mathrm{pH}, \mathrm{GV}$ : gastric fluid volume, Hypergastrinemia: plasma gastrin level $>200 \mathrm{pg} / \mathrm{mL},{ }^{*} p<0.05 \mathrm{vs}$ both $\mathrm{CPB}-\mathrm{H}_{2}$ and CPB-PPI.

Therefore, preanesthetic PPI may be the most appropriate antiacid for patients undergoing cardiac surgery with CPB.

In conclusion, the present study suggests that both gastric fluid volume and blood lactate level may predict the degree of GI tract hypoperfusion. As CPB often increases gastric fluid volume more than $25 \mathrm{~mL}$, gastric tube should be placed before the end of surgery.

\section{Acknowledgment}

The authors thank Professor DG Lambert (University Department of Cardiovascular Sciences, Division of Anaesthesia,
Critical Care and Pain Management, Leicester Royal infirmary, UK) for his valuable comments.

\section{Abbreviations}

CABG coronary artery bypass graft

CPB cardiopulmonary bypass

GI gastrointestinal

GV gastric fluid volume

NSAIDs nonsteroidal antiinflammatory drugs

OPCAB off-pump coronary artery bypass grafting

PPI proton pump inhibitor

\section{References}

1 Geissler HJ, Fischer UM, Grunert S, and et al. Incidence and outcome of gastrointestinal complications after cardiopulmonary bypass. Interact Cardiovasc Thorac Surg 2006; 5: 239-242.

2 van der Voort PH, Zandstra DF. Pathogenesis, risk factors, and incidence of upper gastrointestinal bleeding after cardiac surgery: is specific prophylaxis in routine bypass procedures needed? J Cardiothorac Vasc Anesth 2000; 14: 293-299.

3 Ueki M, Nimura A, Watanabe Y, Maemura T, Konno S. Gastric juice secretion increases during extracorporeal circulation employed in cardiac surgery. Masui 1994; 43: 1020-1023.

4 Tanaka S, Nishigaki K, Ojio S, and et al. Can negative cardiac effect of proton pump inhibitor and high-dose $\mathrm{H}_{2}$-blocker have clinical influence on patients with stable angina? J Cardiol 2008; 52: 39-48.

5 Steinberg KP. Stress-related mucosal disease in the critically ill patient: risk factors and strategies to prevent stress-related bleeding in the intensive care unit. Crit Care Med 2002; 30 Suppl: S362-S364.

6 Hirota K, Kushikata T. Preanaesthetic $\mathrm{H}_{2}$ antagonists for acid aspiration pneumonia prophylaxis. Is there evidence of tolerance? Br J Anaesth 2003; 90: $576-579$.

7 Hirota K, Kudo M, Kushikata T, Hashimoto H, Matsuki A. Regular Use of $\mathrm{H}_{2}$ antagonists reduces preanaesthetic efficacy for acid aspiration pneumonia prophylaxis in anaesthesia patients. Can J Anesth 2005; 52: 166-171.

8 Hurlimann S, Abbühl B, Inauen W, Halter F. Comparison of acid inhibition by either oral high-dose ranitidine or omeprazole. Aliment Pharmacol Ther 1994; 8: 193-201.

9 Netzer P, Gaia C, Sandoz M, and et al. Effect of repeated injection and continuous infusion of omeprazole and ranitidine on intragastric $\mathrm{pH}$ over 72

hours. Am J Gastroenterol 1999; 94: 351-357.

10 Jacobs BR, Swift CA, Dubow HD, and et al. Time required for oral ranitidine to decrease gastric fluid acidity. Anesth Analg 1991; 73: 787-789.

11 Ohri SK, Bjarnason I, Pathi V, and et al. Cardiopulmonary bypass impirs small intestinal transport and increase gut permeability. Ann Thorac Syrg 1993; 55: 1080-1086.

12 Ohri SK, Somasundaram S, Koak Y, and et al. The effect of intestinal hypoperfusion on intestinal absorption and permeability during cardiopulmonary bypass. Gastroenterology 1994; 106: 318-323.

13 Cox CS Jr., Allen SJ. Bernman M. Analysis of intestinal microvascular permiability associated with cardiopulmonary bypass. J Surg Res 1999; 83: 19-26.

14 Tsunooka N, Maeyama K, Hamada Y, and et al. Bacterial translocation secondary to small intestinal mucosal ischemia during cardiopulmonary bypass. Measurement by diamine oxidase and peptidoglycan. Eur J Cardiothorac Surg 2004; 25: 275-280.

15 Roberts RB, Shirley MA. Reducing the risk of acid aspiration during cesarean section. Anesth Analg 1974; 53: 859-868.

16 Hashimoto H, Kushikata T, Kudo M, Hirota K. Does long-term medication of proton pump inhibitor induce a tolerance to $\mathrm{H}_{2}$ receptor antagonist? $J$ Gastroenterol 2007; 42: 275-278.

17 Wagner BK, Amory DW, Majcher CM, DiFazio LT, Scott GE, Spotnitz AJ. Effects of intravenous famotidine on gastric acid secretion in patients undergoing cardiac surgery. Ann Pharmacother 1995; 29: 349-353.

18 Hata M, Shiono M, Sekino H, and et al. Prospective randomized trial for optimal prophylactic treatment of the upper gastrointestinal complications after open heart surgery. Circ J 2005; 69: 331-334. 